Appl. Set-Valued Anal. Optim. 2 (2020), No. 2, pp. 223-233

Available online at http://asvao.biemdas.com

https://doi.org/10.23952/asvao.2.2020.2.07

\title{
A GENERAL SPLIT FIXED POINT PROBLEM GOVERNED BY DEMICONTRACTIVE MAPPINGS IN BANACH SPACES
}

\author{
HABTU ZEGEYE*, OGANEDITSE A. BOIKANYO \\ Department of Mathematics and Statistical Sciences, \\ Botswana International University of Science and Technology, Palapye, Botswana
}

\begin{abstract}
In this paper, we introduce an iterative process, which converges strongly to the solution of a general split fixed point problem governed by demicontractive mappings and prove strong convergence theorems in Banach spaces.
\end{abstract}

Keywords. Demicontractive mappings; Nonexpansive mapping; Split fixed point problem; Strong convergence.

\section{INTRODUCTION}

Let $C$ be a nonempty, closed and convex subset of a real Banach space $E$. Let $T: C \rightarrow C$ be a nonlinear mapping and let the fixed point set of $T$ be denoted by $F(T)$. Let $f: E \rightarrow \mathbb{R}$ be a nonnegative lower semicontinuous (1.s.c) convex function. Recall that the general split fixed point problem (GSFPP) is to

$$
\text { find } x^{*} \in F(T) \text { such that } f\left(x^{*}\right)=0 \text {. }
$$

The solution set of the general split fixed point problem is denoted by $\Omega$. If, in (1.1), $E=$ $E_{1} \times E_{2}$, where $E_{1}$ and $E_{2}$ are real Banach spaces, and $f: E \rightarrow \mathbb{R}$ and $T: E \rightarrow E$ are defined by

$$
f(x, y)=\frac{1}{2}\|A x-B y\|^{2} \text { and } T(x, y)=\left(T_{1} x, T_{2} y\right),
$$

where $A: E_{1} \rightarrow E_{3}$ and $B: E_{2} \rightarrow E_{3}$ are two bounded linear mappings, where $E_{3}$ the third real Banach space, and $T_{1}: E_{1} \rightarrow E_{1}$ and $T_{2}: E_{2} \rightarrow E_{2}$ are nonlinear mappings. Then, we can easily see that $F(T)=F\left(T_{1}\right) \times F\left(T_{2}\right)$ and problem (1.1) coincides with the split equality fixed point problem (SEFPP) given by

$$
\text { find } x^{*} \in F\left(T_{1}\right) \text { and } y^{*} \in F\left(T_{2}\right) \text { such that } A x^{*}=B y^{*} \text {, }
$$

which allows asymmetric and partial relations between the variables $x$ and $y$. The interest in SEFPP is to cover many situations, for instance, fully discretized models of inverse problems, which arise from medical image reconstruction; see, e.g., $[3,5,6])$.

${ }^{*}$ Corresponding author.

E-mail addresses: habtuzh@yahoo.com (H. Zegeye), boikanyoa@gmail.com (O.A. Boikanyo).

Received May 12, 2020; Accepted July 1, 2020.

(C)2020 Applied Set-Valued Analysis and Optimization 
If, in (1.2), $E_{2}=E_{3}$ and $B=I$, the identity mapping, then split equality problem (1.2) is reduced to the following split common fixed point problem (SCFPP) (originally introduced in Censor and Segal [3]), which is to

$$
\text { find } x^{*} \in F\left(T_{1}\right) \text { such that } A x^{*} \in F\left(T_{2}\right) \text {. }
$$

The problem SCFPP is a core for modelling many significant real-world inverse problems, such as, radiation therapy treatment planning, data compression, magnetic resonance imaging, neural networks and graph matching. For more details and other examples, we refer to $[2,12]$ and the references therein.

Recently, many authors proposed various methods for solving the problems related to SEFPP and SCFPP or their particular cases; see, e.g., [2, 4, 5, 7, 8, 9, 11]. However, most of them used the iterative methods, which depend on the associated operator norms $\|A\|$ and $\|B\|$. This may not be an easy task to compute in applications. To overcome this numerical drawback, many authors further proposed some new iterative methods for solving the problems of SEFPP and SCFPP governed by some type of nonlinear mappings without requiring any prior knowledge of the associated operator norms; see, e.g., [12, 18, 19, 20].

Now, we give the definitions of the nonlinear mappings involved in this paper. Let $C$ be a nonempty subset of a real Banach space $E$ whose dual is denoted by $E^{*}$. A mapping $T: C \rightarrow E$ is said to be L-Lipschitz if

$$
\|T x-T y\| \leq L\|x-y\|, \quad \forall x, y \in C .
$$

If $L=1$, then $T$ is said to be nonexpansive. Recall that $T$ is said to be quasi-nonexpansive if $F(T) \neq \emptyset$ and

$$
\left\|T x-T x^{*}\right\| \leq\left\|x-x^{*}\right\|, \quad \forall x \in C, x^{*} \in F(T) .
$$

$T$ is said to be firmly quasi-nonexpansive if $F(T) \neq \emptyset$ and

$$
\left\|T x-T x^{*}\right\|^{2} \leq\left\|x-x^{*}\right\|^{2}-\|x-T x\|^{2}, \quad \forall x \in C, x^{*} \in F(T) .
$$

We observe that the class of quasi-nonexpansive mappings includes the class of nonexpansive mappings with $F(T) \neq \emptyset$ and the class of firmly quasi-nonexpansive mappings.

Recall that a mapping $T: C \rightarrow E$ is said to be $k$-strictly pseudocontractive if there exists $k \in(0,1)$ such that

$$
\left\langle T x-T y, j_{q}(x-y)\right\rangle \leq\|x-y\|^{q}-k\|x-y-(T x-T y)\|^{q}, \quad \forall x, y \in C,
$$

for $j_{q}(x) \in J_{q}(x)$, where $J_{q}$ is defined by

$$
J_{q}(x):=\left\{x^{*} \in E^{*}:\left\langle x, x^{*}\right\rangle=\|x\|^{q},\left\|x^{*}\right\|=\|x\|^{q-1}\right\},
$$

for $q>1$. In particular, $J_{q}=J_{2}=J$ is called the normalized duality mapping. It is known that $E$ is smooth if and only if $J_{q}$ is single-valued. Furthermore, we have the following properties:

1. $J_{q}(x)=\|x\|^{q-2} J(x)$ for all $x \in E$ with $x \neq 0$.

2. $J_{q}(t x)=t^{q-1} J_{q}(x)$ for all $x \in E$ and $t \in[0, \infty)$.

3. $J_{q}(-x)=-J_{q}(x)$ for all $x \in E$.

It is known that if $E$ is uniformly smooth and uniformly convex, then the duality mapping $J_{p}$ from $E^{*}$ into $2^{E}$, where $p>1$ such that $\frac{1}{q}+\frac{1}{p}=1$, is one-to-one, single-valued and satisfies $J_{p}=\left(J_{q}\right)^{-1}$ (see [13]). If $E:=H$ is a real Hilbert space, then $q=2$ and $J_{2}=J=I$, where $I$ is the identity mapping. The duality mapping $J_{q}$ from a smooth Banach space $E$ into $E^{*}$ is said to 
be weakly sequentially continuous generalized duality mapping if, for all $\left\{x_{n}\right\} \subset E$ with $x_{n} \rightarrow x$, $J_{q}\left(x_{n}\right) \rightarrow^{*} J_{q}(x)$.

Recall that $T$ is said to be demicontractive if $F(T) \neq \emptyset$ and there exists $k \in(0,1)$ such that

$$
\left\langle T x-x^{*}, j_{q}\left(x-x^{*}\right)\right\rangle \leq\left\|x-x^{*}\right\|^{q}-k\|x-T x\|^{q} \text {, for all } x \in C, x^{*} \in F(T) .
$$

We remark that in Hilbert spaces, (1.4) and (1.5) are equivalent to the inequalities

$$
\|T x-T y\|^{2} \leq\|x-y\|^{2}+\kappa\|(x-y)-(T x-T y)\|^{2}, \text { for } \kappa=(1-2 k)<1,
$$

and

$$
\left\|T x-T x^{*}\right\|^{2} \leq\left\|x-x^{*}\right\|^{2}+\kappa\|x-T x\|^{2}, \text { for } \kappa=(1-2 k)<1,
$$

respectively. Clearly, every $k$-strictly pseudocontractive mapping $T$ with a nonempty fixed point set is demicontractive. In addition, we observe that, in Hilbert spaces, the class of demicontractive mappings includes the class of quasi-nonexpansive and hence the class of firmly quasi-nonexpansive mappings. In [18, 19], the authors obtained weak convergence results to a solution of the split equality fixed point problem (1.2) governed by quasi-nonexpansive operators. On the other hand, Zhao and Zhang [20] proved a strong convergence result under the assumption that the mapping $T$ is firmly quasi-nonexpansive. More recently, Giang et al. [10] constructed an iterative scheme for approximating solutions of the problem (1.1) governed by quasi-nonexpansive mappings and proved the strong convergence of the scheme in Hilbert spaces. These works lead to the following important question.

Question 1.1. Can we obtain an iterative scheme, which converges strongly to a solution of the general split fixed point problem governed by a more general class of mappings in Banach spaces?

In this paper, it is our purpose to construct an algorithm, which converges strongly to a solution of the problem (1.1) governed by demicontractive self mappings without requiring any prior knowledge of the associated operator norms in $q$-uniformly smooth Banach spaces. Our theorems extend and complement the existing results in this research direction.

\section{PRELIMINARIES}

Let $E$ be a real Banach Space. The modulus of smoothness of $E$ is the function $\rho_{E}:[0, \infty) \rightarrow$ $[0, \infty)$ defined by

$$
\rho_{E}(\tau):=\sup \left\{\frac{1}{2}(\|x+y\|+\|x-y\|)-1:\|x\|=1,\|y\|=\tau\right\} .
$$

If $\rho_{E}(\tau)>0$ for all $\tau>0$, then $E$ is said to be smooth. If there exists a constant $c>0$ and a real number $1<q<\infty$ such that $\rho_{E}(\tau) \leq c \tau^{q}$, then $E$ is said to be $q$-uniformly smooth.

It is known (see, for example, [1]) that

$$
L_{p}\left(l_{p}\right) \text { or } W_{m}^{p} \text { is }\left\{\begin{array}{l}
q \text {-uniformly smooth } \text { if } 1<q<2 \\
2 \text {-uniformly smooth if } q \geq 2 .
\end{array}\right.
$$


If $E$ is a $q$-uniformly smooth real Banach space, we have from [15] the following geometric inequality

$$
\|x+y\|^{q} \leq\|x\|^{q}+q\left\langle y, J_{q}(x)\right\rangle+c_{q}\|y\|^{q}
$$

for all $x, y \in E$, where $c_{q}>0$ is the best $q$-uniformly smooth constant of the space. If $E=H$, a real Hilbert space, then $q=2$ and $c_{q}=1$.

A real Banach space $E$ is called strictly convex if, for all $x, y \in E, x \neq y,\|x\|=\|y\|=1$, $\| \lambda x+(1-\lambda) y||<1, \forall \lambda \in(0,1)$. The Banach space $E$ is said to be uniformly convex if, $\forall \varepsilon>0$, there exists $\delta>0$ such that, for all $x, y \in E$ with $\|x\| \leq 1,\|y\| \leq 1$ and $\|x-y\| \geq \varepsilon$, $\left\|\frac{1}{2}(x+y)\right\| \leq 1-\delta$. It is well known that $L_{p}, \ell_{p}$ and Sobolev spaces $W_{m}^{p},(1<p<\infty)$, are uniformly convex. It is also known that $E$ is $q$-uniformly smooth if and only if $E^{*}$ is $p$-uniformly convex, where $p>1$ satisfying $\frac{1}{p}+\frac{1}{q}=1$ (see, e.g., [13]).

Let $C$ be a nonempty, closed and convex subset of $E$. The metric projection

$$
P_{C} x=\arg \min _{y \in C}\|x-y\|, x \in E,
$$

is the unique minimizer of the norm distance, which can be characterized by the following variational inequality:

$$
\left\langle x-P_{C} x, J_{q}\left(z-P_{C} x\right)\right\rangle \leq 0, \forall z \in C .
$$

We next state the following lemmas, which will be used in the sequel.

Lemma 2.1. [15] Let $p>1$, and $r>0$ be two fixed real numbers. Then $E$ is uniformly convex if and only if there exists a continuous, strictly increasing and convex function

$$
g: \mathbb{R}^{+} \rightarrow \mathbb{R}^{+}, g(0)=0,
$$

such that, for all $x, y \in B_{r}=\{x \in E:\|x\| \leq r\}$ and $0 \leq \lambda \leq 1$,

$$
\|\lambda x+(1-\lambda) y\|^{p} \leq \lambda\|x\|^{p}+(1-\lambda)\|y\|^{p}-W_{p}(\lambda) g(\|x-y\|),
$$

where $W_{p}(\lambda):=\lambda^{p}(1-\lambda)+\lambda(1-\lambda)^{p}$.

Lemma 2.2. [17] Let $E$ be a real q-uniformly smooth Banach space, and let $C$ be a closed convex subset of $E$. Let $T: C \rightarrow C$ be a demicontractive mapping with constant $k$ and $F(T) \neq \emptyset$. For $\alpha \in(0,1)$, we define $T_{\alpha} x:=(1-\alpha) x+\alpha T x$, for all $x \in C$. If $\alpha \in[0, \mu]$, where $\mu=$ $\min \left\{1,\left(\frac{q k}{c_{q}}\right)^{\frac{1}{q-1}}\right\}$, then $F(T)=F\left(T_{\alpha}\right)$ and

$$
\left\|T_{\alpha} x-T_{\alpha} x^{*}\right\|^{q} \leq\left\|x-x^{*}\right\|^{q}-\alpha\left(q k-c_{q} \alpha^{q-1}\right)\|(x-T x)\|^{q} .
$$

Lemma 2.3. [15] Let $E$ be a real normed linear space, and $J_{q}: E \rightarrow 2^{E^{*}}, 1<q<\infty$, be the generalized duality mapping. Then, for any $x, y \in E$, the following inequality holds.

$$
\|x+y\|^{q} \leq\|x\|^{q}+q\left\langle y, j_{q}(x+y)\right\rangle,
$$

for all $j_{q}(x+y) \in J_{q}(x+y)$.

Lemma 2.4. [17] Let $C$ be a nonempty, closed and convex subset of a real q-uniformly smooth space $E$. Let $T_{i}: C \rightarrow E, i=1, \ldots, N$, be $\lambda_{i}$-strictly pseudocontractive mappings such that $\cap_{i=1}^{N} F\left(T_{i}\right) \neq \emptyset$. Let $T:=\theta_{1} T_{1}+\theta_{2} T_{2}+\ldots+\theta_{N} T_{N}$ with $\theta_{1}+\theta_{2}+\ldots+\theta_{N}=1$. Then $T$ is $\lambda$ strictly pseudocontractive with $\lambda:=\min \left\{\lambda_{i}: i=1,2, \ldots, N\right\}$ and $F(T)=\cap_{i=1}^{N} F\left(T_{i}\right)$. 
Lemma 2.5. [21] Let $E$ be a real uniformly convex Banach space, and let $K$ a be nonempty closed convex subset of $E$. Let $T: K \rightarrow K$ be a continuous pseudo-contractive mapping. Then, $(I-T)$ is demiclosed at zero, that is, for any sequence $\left\{x_{n}\right\} \subset C$ with $\left\{x_{n}\right\}$ converging weakly to $x^{*}$, and $x_{n}-T x_{n} \rightarrow 0$, we have $x^{*}=T x^{*}$.

Lemma 2.6. [16] Let $\left\{a_{n}\right\}$ be a nonnegative real number sequences such that

$$
a_{n+1} \leq\left(1-\alpha_{n}\right) a_{n}+\alpha_{n} \delta_{n}, n \geq n_{0},
$$

where $\left\{\alpha_{n}\right\} \subset(0,1)$ and $\left\{\delta_{n}\right\} \subset \mathbb{R}$ satisfy the following conditions: $\limsup _{n \rightarrow \infty} \delta_{n} \leq 0$ and $\sum_{n=1}^{\infty} \alpha_{n}=$ $\infty$. Then, $\lim _{n \rightarrow \infty} a_{n}=0$.

Lemma 2.7. [14] Let $\left\{a_{n}\right\}$ be real number sequence such that there exists a subsequence $\left\{n_{i}\right\}$ of $\{n\}$, which satisfies $a_{n_{i}}<a_{n_{i}+1}$ for all $i \in N$. Then there exists a nondecreasing sequence $\left\{m_{k}\right\} \subset N$ such that $m_{k} \rightarrow \infty$ and the following properties are satisfied by all (sufficiently large) numbers $k \in N: a_{m_{k}} \leq a_{m_{k}+1}$ and $a_{k} \leq a_{m_{k}+1}$. Indeed, $m_{k}=\max \left\{j \leq k: a_{j}<a_{j+1}\right\}$.

\section{MAIN RESUlT}

For the rest of this paper, let $E$ be a $q$-uniformly smooth $(1<q<\infty)$ and uniformly convex real Banach spaces $E$ with $c_{q} \leq 1$, where $c_{q}$ is a constant in (2.1). Let $f: E \rightarrow \mathbb{R}$ be nonnegative 1.s.c. convex function with $d_{n}$ a search direction and

$$
\lambda_{n}= \begin{cases}\frac{\rho_{n} f\left(x_{n}\right)}{\left\|d_{n}\right\|^{p}}, & d_{n} \neq 0 \\ 0, & \text { otherwise, }\end{cases}
$$

where $\rho_{n} \in(0, q)$ and $p>1$ such that $\frac{1}{q}+\frac{1}{p}=1$, with the following Assumptions:

A1. $\left\langle d_{n}, x_{n}-x^{*}\right\rangle \geq f\left(x_{n}\right)$ for all $n \in \mathbb{N}$ and for all $x^{*} \in \Omega=\{x \in F(T): f(z)=0\} ;$

A2. $0<\bar{\lambda} \leq \lambda_{n} \leq \overline{\bar{\lambda}}$ for all $n \in \Gamma:=\left\{n \in \mathbb{N}: d_{n} \neq 0\right\}$ for some $\bar{\lambda}, \overline{\bar{\lambda}} \in \mathbb{R}$ and

A3. $\inf _{n \in \Gamma}\left[\rho_{n}^{q-1}\left(q-\rho_{n}\right)\right]>0$.

We remark that any vector $d_{n} \in \partial f\left(x_{n}\right)$, where $\partial f$ is the subdifferential of $f$, is an example of direction vector satisfying Assumption (A1). Indeed, since $f\left(x^{*}\right)=0$, we have from the definition of the subdifferential of a convex function that

$$
0 \geq f\left(x_{n}\right)+\left\langle d_{n}, x^{*}-x_{n}\right\rangle .
$$

Thus, Assumption (A1) is satisfied.

Now, we are in a position to prove the following theorem.

Theorem 3.1. Let $T: E \rightarrow E$ be a demicontractive mapping. Assume that $\Omega:=\left\{x^{*} \in F(T)\right.$ : $\left.f\left(x^{*}\right)=0\right\} \neq \emptyset$. For arbitrary $x_{0}, u \in E$, we define an iterative algorithm by

$$
\left\{\begin{array}{l}
u_{n}=x_{n}-\lambda_{n} J_{q}^{-1} d_{n} \\
\left.x_{n+1}=\alpha_{n} u+\left(1-\alpha_{n}\right)\left(\left(1-b_{n}\right) u_{n}+b_{n} T u_{n}\right)\right)
\end{array}\right.
$$

where $b_{n} \in(c, \mu] \subset(0,1)$ for some $c>0$ and $\mu<\min \left\{1,\left\{\frac{q k}{c_{q}}\right\}^{\frac{1}{q-1}}\right\}$ for all $n \geq 0$, and $\left\{\alpha_{n}\right\} \subset$ $(0,1), \forall n \geq 0$. Then $\left\{x_{n}\right\}$ is bounded. 
Proof. Let $x^{*} \in \Omega$, that is, $x^{*} \in F(T)$ and $f\left(x^{*}\right)=0$. Now, from (3.2) and inequality (2.1), we get

$$
\begin{aligned}
\left\|u_{n}-x^{*}\right\|^{q} & =\left\|\left(x_{n}-x^{*}\right)-\lambda_{n} J_{q}^{-1} d_{n}\right\|^{q} \\
& \leq\left\|\lambda_{n} J_{q}^{-1} d_{n}\right\|^{q}-q \lambda_{n}^{q-1}\left\langle x_{n}-x^{*}, d_{n}\right\rangle+c_{q}\left\|x_{n}-x^{*}\right\|^{q} \\
& \leq \lambda_{n}^{q}\left\|d_{n}\right\|^{p}-q \lambda_{n}^{q-1}\left\langle x_{n}-x^{*}, d_{n}\right\rangle+c_{q}\left\|x_{n}-x^{*}\right\|^{q} \\
& \leq\left\|x_{n}-x^{*}\right\|^{q}-q \lambda_{n}^{q-1} f\left(x_{n}\right)+\lambda_{n}^{q}\left\|d_{n}\right\|^{p} \\
& =\left\|x_{n}-x^{*}\right\|^{q}-q \rho_{n}^{q-1} \frac{f\left(x_{n}\right)^{q}}{\left\|d_{n}\right\|^{q}}+\rho_{n}^{q} \frac{f\left(x_{n}\right)^{q}}{\left\|d_{n}\right\|^{q}} \\
& =\left\|x_{n}-x^{*}\right\|^{q}-\rho_{n}^{q-1}\left(q-\rho_{n}\right) \frac{f\left(x_{n}\right)^{q}}{\left\|d_{n}\right\|^{q}} \\
& \leq\left\|x_{n}-x^{*}\right\|^{q},
\end{aligned}
$$

Furthermore, from (3.2), Lemmas 2.1 and ??, and the definition of $\lambda_{n}$, we find

$$
\begin{aligned}
\left\|x_{n+1}-x^{*}\right\|^{q}= & \left\|\alpha_{n}\left(u-x^{*}\right)+\left(1-\alpha_{n}\right)\left(\left(1-b_{n}\right) u_{n}+b_{n} T u_{n}-x^{*}\right)\right\|^{q} \\
\leq & \alpha_{n}\left\|u-x^{*}\right\|^{q}+\left(1-\alpha_{n}\right)\left\|\left(1-b_{n}\right) u_{n}+b_{n} T u_{n}-x^{*}\right\|^{q} \\
\leq & \alpha_{n}\left\|u-x^{*}\right\|^{q}+\left(1-\alpha_{n}\right)\left[\left\|u_{n}-x^{*}\right\|^{q}\right. \\
& \left.-b_{n}\left(q k-c_{q} b_{n}^{q-1}\right)\left\|T u_{n}-u_{n}\right\|^{q}\right] \\
\leq & \alpha_{n}\left\|u-x^{*}\right\|^{q}+\left(1-\alpha_{n}\right)\left\|x_{n}-x^{*}\right\|^{q}-\left(1-\alpha_{n}\right) \rho_{n}^{q-1}\left(q-\rho_{n}\right) \frac{f\left(x_{n}\right)^{q}}{\left\|d_{n}\right\|^{q}} \\
& -\left(1-\alpha_{n}\right) b_{n}\left(q k-c_{q} b_{n}^{q-1}\right)\left\|T u_{n}-u_{n}\right\|^{q} .
\end{aligned}
$$

From the hypothesis, we have

$$
q k-c_{q} b_{n}^{q-1}>0 \text { and } \inf _{n \rightarrow \infty} \rho_{n}^{q-1}\left(q-\rho_{n}\right)>0
$$

Thus, inequality (3.5) implies that

$$
\left\|x_{n+1}-x^{*}\right\|^{q} \leq \alpha_{n}\left\|u-x^{*}\right\|^{q}+\left(1-\alpha_{n}\right)\left\|x_{n}-x^{*}\right\|^{q}
$$

It follows that

$$
\left\|x_{n+1}-x^{*}\right\|^{q} \leq \max \left\{\left\|u-x^{*}\right\|^{q},\left\|x_{0}-x^{*}\right\|^{q}\right\}, \forall n \geq 0
$$

which shows that $\left\{x_{n}\right\}$ and $\left\{u_{n}\right\}$ are bounded. This completes the proof.

Theorem 3.2. Let $E$ admit a weakly sequentially continuous generalized duality mapping. Let $T: E \rightarrow E$ be a demicontractive mapping such that $(I-T)$ is demiclosed at zero. Assume that $\Omega:=\left\{x^{*} \in F(T): f\left(x^{*}\right)=0\right\} \neq \emptyset$ and $\left\{\alpha_{n}\right\} \subset(0, d] \subset(0,1)$ for some $d>0$, satisfying $\lim _{n \rightarrow \infty} \alpha_{n}=0, \sum_{n=0}^{\infty} \alpha_{n}=\infty$. Let the sequence $\left\{x_{n}\right\}$ be defined by (3.2). Then, $\left\{x_{n}\right\}$ converges strongly to an element $x^{*}=P_{\Omega} u \in \Omega$, where $P_{\Omega}$ is the metric projection onto $\Omega$ 
Proof. From Theorem 3.1, we have that $\left\{x_{n}\right\}$ is bounded. Let $x^{*}=P_{\Omega} u$. Now, from (3.2), Lemmas ??, 2.3 and (3.3), we get that

$$
\begin{aligned}
\left\|x_{n+1}-x^{*}\right\|^{q}= & \left\|\alpha_{n} u+\left(1-\alpha_{n}\right)\left(\left(1-b_{n}\right) u_{n}+b_{n} T u_{n}\right)-x^{*}\right\|^{q} \\
= & \left\|\alpha_{n}\left(u-x^{*}\right)+\left(1-\alpha_{n}\right)\left(\left(1-b_{n}\right) u_{n}+b_{n} T u_{n}-x^{*}\right)\right\|^{q} \\
\leq & \left(1-\alpha_{n}\right)\left\|\left(1-b_{n}\right) u_{n}+b_{n} T u_{n}-x^{*}\right\|^{q} \\
& +q \alpha_{n}\left\langle u-x^{*}, J_{q}\left(x_{n+1}-x^{*}\right)\right\rangle \\
\leq & \left(1-\alpha_{n}\right)\left\|u_{n}-x^{*}\right\|^{q}+q \alpha_{n}\left\langle u-x^{*}, J_{q}\left(x_{n+1}-x^{*}\right)\right\rangle \\
& -\left(1-\alpha_{n}\right)\left(q k-c_{q} b_{n}^{q-1}\right) b_{n}\left\|(I-T) u_{n}\right\|^{q} \\
\leq & \left(1-\alpha_{n}\right)\left\|x_{n}-x^{*}\right\|^{q}+q \alpha_{n}\left\langle u-x^{*}, J_{q}\left(x_{n+1}-x^{*}\right)\right\rangle \\
& -\rho_{n}^{q-1}\left(q-\rho_{n}\right)\left(1-\alpha_{n}\right) \frac{f\left(x_{n}\right)^{q}}{\left\|d_{n}\right\|^{q}}-\left(1-\alpha_{n}\right)\left(q k-c_{q} b_{n}^{q-1}\right) b_{n} \\
& \times\left\|(I-T) u_{n}\right\|^{q} .
\end{aligned}
$$

Next, we show that the sequence $\left\{\left\|x_{n}-x^{*}\right\|\right\}$ converges strongly to zero. For this, we consider two possible cases on $\left\{\left\|x_{n}-x^{*}\right\|\right\}$.

Case 1. Suppose that there exists $n_{0} \in \mathbb{N}$ such that $\left\{\left\|x_{n}-x^{*}\right\|\right\}$ is decreasing for all $n \geq n_{0}$. In this situation, $\left.\left\{\| x_{n}-x^{*}||\right)\right\}$ is convergent. Thus, from (3.8), the hypothesis and the fact that $\alpha_{n} \rightarrow 0$, as $n \rightarrow \infty$, we obtain

$$
\frac{f\left(x_{n}\right)^{q}}{\left\|d_{n}\right\|^{q}} \rightarrow 0 \text { and } \quad\left\|(I-T) u_{n}\right\|^{q} \rightarrow 0, \text { as } n \rightarrow \infty
$$

which yields

$$
\frac{f\left(x_{n}\right)}{\left\|d_{n}\right\|} \rightarrow 0 \quad \text { and } \quad\left\|(I-T) u_{n}\right\| \rightarrow 0, \text { as } n \rightarrow \infty
$$

Since $0<\bar{\lambda} \leq \lambda_{n}=\rho_{n} \frac{f\left(x_{n}\right)}{\left\|d_{n}\right\|^{p}} \leq \overline{\bar{\lambda}}$, we obtain

$$
\begin{aligned}
\lambda_{n}\left(\left\|d_{n}\right\|^{p-1}\right) & =\rho_{n} \frac{f\left(x_{n}\right)}{\left\|d_{n}\right\|^{p}}\left(\left\|d_{n}\right\|^{p-1}\right) \\
& =\rho_{n} \frac{f\left(x_{n}\right)}{\left\|d_{n}\right\|^{p}}\left(\frac{\left\|d_{n}\right\|^{q-1}}{\left\|d_{n}\right\|^{q-p}}\right) \\
& =\rho_{n} \frac{f\left(x_{n}\right)}{\left\|d_{n}\right\|} \rightarrow 0,
\end{aligned}
$$

which implies $\left\|d_{n}\right\| \rightarrow 0$ as $n \rightarrow \infty$. Therefore, from this and (3.10), we derive $f\left(x_{n}\right) \rightarrow 0$ as $n \rightarrow \infty$. It follows from (3.2) that

$$
\left\|x_{n}-u_{n}\right\|=\lambda_{n}|| J_{q}^{-1} d_{n} \| \rightarrow 0, \text { as } n \rightarrow \infty,
$$

and

$$
|| x_{n+1}-u_{n}\left\|\leq \alpha_{n}\right\| u-u_{n}\left\|+\left(1-\alpha_{n}\right) b_{n}\right\| T u_{n}-u_{n} \| \rightarrow 0,
$$

as $n \rightarrow \infty$. Consequently, we have that

$$
\left\|x_{n+1}-x_{n}\right\| \rightarrow \infty \text {, as } n \rightarrow \infty .
$$


Next, we show that $x_{n} \rightarrow x^{*}$. Since, the sequence $\left\{x_{n}\right\} \subset E$ is bounded we can extract a subsequence $\left\{x_{n_{k}}\right\}$ of $\left\{x_{n}\right\}$, which converges weakly to $z \in E$ and

$$
\limsup _{n \rightarrow \infty}\left\langle u-x^{*}, J_{q}\left(x_{n}-x^{*}\right)\right\rangle=\lim _{k \rightarrow \infty}\left\langle u-x^{*}, J_{q}\left(x_{n_{k}}-x^{*}\right)\right\rangle .
$$

Thus, from (3.11), we have that $\left\{u_{n_{k}}\right\}$ converges weakly to $z$. Now, by demiclosedness of $(I-T)$ and (3.9) we get that $z \in F(T)$. Furthermore, since $f$ is nonnegative weakly l.s.c., we obtain

$$
0 \leq f(z) \leq \liminf _{k \rightarrow \infty} f\left(x_{n_{k}}\right)=0,
$$

where we have used the fact that $f\left(x_{n_{k}}\right) \rightarrow 0$ as $n \rightarrow \infty$. Therefore, from the above discussions, we obtain $z \in \Omega$. From (3.14), (3.13) and inequality (2.2), we obtain that

$$
\limsup _{n \rightarrow \infty}\left\langle u-x^{*}, J_{q}\left(x_{n+1}-x^{*}\right)\right\rangle=\left\langle u-x^{*}, J_{q}\left(z-x^{*}\right)\right\rangle \leq 0 .
$$

Therefore, it follows from (3.8), (3.16) and Lemma 2.6 that $\left\|x_{n}-x^{*}\right\| \rightarrow 0$ as $n \rightarrow \infty$. Consequently, $x_{n} \rightarrow x^{*} \in \Omega$.

Case 2. Suppose that, for each $n_{0} \in \mathbb{N},\left\{|| x_{n}-x^{*}||\right\}_{n \geq n_{0}}$ is not decreasing. Then there exists a subsequence $\left\{n_{i}\right\}$ of $\{n\}$ such that

$$
\left\|x_{n_{i}}-x^{*}\right\|^{q}<\left\|x_{n_{i}+1}-x^{*}\right\|^{q},
$$

for all $i \in \mathbb{N}$. Using Lemma 2.7, we have that there exists a nondecreasing sequence $\left\{m_{k}\right\} \subset \mathbb{N}$ such that $m_{k} \rightarrow \infty$ and

$$
\left\|x_{m_{k}}-x^{*}\right\|^{q} \leq\left\|x_{m_{k}+1}-x^{*}\right\|^{q} \text { and }\left\|x_{k}-x^{*}\right\|^{q} \leq\left\|x_{m_{k}+1}-x^{*}\right\|^{q},
$$

for all $k \in \mathbb{N}$. Thus, following the method in Case 1 and the fact that $\alpha_{n} \rightarrow 0$, we have that $u_{m_{k}}-T u_{m_{k}} \rightarrow 0, f\left(x_{m_{k}}\right) \rightarrow 0,\left\|d_{m_{k}}\right\| \rightarrow 0$ as $k \rightarrow \infty$. Hence,

$$
\limsup _{k \rightarrow \infty}\left\langle u-x^{*}, J_{q}\left(x_{m_{k}+1}-x^{*}\right)\right\rangle \leq 0 .
$$

Furthermore, from (3.8), we get that

$$
\left\|x_{m_{k}+1}-x^{*}\right\|^{q} \leq\left(1-\alpha_{m_{k}}\right)\left\|x_{m_{k}}-x^{*}\right\|^{q}+q \alpha_{m_{k}}\left\langle u-x^{*}, J_{q}\left(x_{m_{k}+1}-x^{*}\right)\right\rangle,
$$

which implies from (3.17) and (3.19) that

$$
\begin{aligned}
\alpha_{m_{k}}|| x_{m_{k}}-x^{*} \|^{q} & \leq\left\|x_{m_{k}}-x^{*}\right\|^{q}-\left\|x_{m_{k}+1}-x^{*}\right\|^{q}+q \alpha_{m_{k}}\left\langle u-x^{*}, J_{q}\left(x_{m_{k}+1}-x^{*}\right)\right\rangle \\
& \leq q \alpha_{m_{k}}\left\langle u-x^{*}, J_{q}\left(x_{m_{k}+1}-x^{*}\right)\right\rangle .
\end{aligned}
$$

In particular, since $\alpha_{m_{k}}>0$, we get

$$
\left\|x_{m_{k}}-x^{*}\right\|^{q} \leq q\left\langle u-x^{*}, J_{q}\left(x_{m_{k}+1}-x^{*}\right)\right\rangle .
$$

Then, using (3.18) we obtain that $\left\|x_{m_{k}}-x^{*}\right\| \rightarrow 0$ as $k \rightarrow \infty$. This together with (3.19) gives that $\left\|x_{m_{k}+1}-x^{*}\right\| \rightarrow 0$ as $k \rightarrow \infty$. But

$$
\left\|x_{k}-x^{*}\right\| \leq\left\|x_{m_{k}+1}-x^{*}\right\|,
$$

for all $k \in \mathbb{N}$. It follows that $x_{k} \rightarrow x^{*}$. Therefore, from the both cases, we can conclude that $\left\{x_{n}\right\}$ converges strongly to a point $x^{*}=P_{\Omega} u$. This completes the proof. 
If, in Theorem 3.2, we assume that $T$ is $k$-strictly pseudoconractive mapping with a nonempty fixed point set $F(T)$, then $I-T$ is demiclosed at zero. Hence we have the following result.

Corollary 3.1. Let $E$ admit a weakly sequentially continuous duality mapping. Let $T: E \rightarrow E$ be a $k$-strictly pseudocontractive mapping. Assume that $\Omega:=\left\{x^{*} \in F(T): f\left(x^{*}\right)=0\right\} \neq \emptyset$ and let $\left\{\alpha_{n}\right\}$ be a real sequence in $(0, d] \subset(0,1)$ for some $d>0$ such that $\sum_{n=0}^{\infty} \alpha_{n}=\infty$ and $\lim _{n \rightarrow \infty} \alpha_{n}=0$. Let $\left\{x_{n}\right\}$ be a sequence defined by (3.2). Then, $\left\{x_{n}\right\}$ converges strongly to an element $x^{*}=P_{\Omega} u \in \Omega$.

If, in Theorem 3.2, $T:=\sum_{i=1}^{N} a_{i} T_{i}$ with $\sum_{i=1}^{N} a_{i}=1$, where $T_{i}, i=1,2, \ldots, N$ are $k_{i}$-strictly pseudocontractive, then we conclude from Lemma 2.4 that $T$ is $k$-strictly pseudocontractive with $k=\max _{i=1}^{N}\left\{k_{i}\right\}$. In fact, we have the following result.

Corollary 3.2. Let $E$ admit a weakly sequentially continuous duality mapping. Let $T_{i}: E \rightarrow E$, $i=1,2, \ldots, N$ be a $k_{i}$-strictly pseudocontractive mapping for each $i$. Assume that $\Omega:=\left\{x^{*} \in\right.$ $\left.\cap_{i=1}^{N} F\left(T_{i}\right): f\left(x^{*}\right)=0\right\} \neq \emptyset$. For arbitrary $x_{0}, u \in E$, we define an iterative algorithm by

$$
\left\{\begin{array}{l}
u_{n}=x_{n}-\lambda_{n} J_{q}^{-1} d_{n}, \\
x_{n+1}=\alpha_{n} u+\left(1-\alpha_{n}\right)\left(\left(1-b_{n}\right) u_{n}+b_{n} T u_{n}\right), \forall n \geq 0,
\end{array}\right.
$$

where $T:=\sum_{i=1}^{N} a_{i} T_{i}$ is $k$-strictly pseudocontractive with $\sum_{i=1}^{N} a_{i}=1, b_{n} \in(c, \mu]$, for some $c>0$ and $\mu<\min \left\{1,\left\{\frac{q k}{c_{q}}\right\}^{\frac{1}{q-1}}\right\}$ for all $n \geq 0$, and $\left\{\alpha_{n}\right\} \subset(0, d] \subset(0,1)$ such that $\sum_{n=0}^{\infty} \alpha_{n}=\infty$ and $\lim _{n \rightarrow \infty} \alpha_{n}=0$. Then, $\left\{x_{n}\right\}$ converges strongly to an element $x^{*}=P_{\Omega} u \in \Omega$.

If, in Theorem 3.2, $E=H$, a real Hilbert space, then $q=2$ and $c_{q}=1$. Hence we have the following theorem in the framework of Hilbert spaces.

Theorem 3.3. Let $C$ be a nonempty, closed and convex subset of a real Hilbert space H. Let $T: C \rightarrow C$ be a demicontractive mapping such that $I-T$ is demiclosed at zero. Assume that $\Omega:=\left\{x^{*} \in F(T): f\left(x^{*}\right)=0\right\} \neq \emptyset$. For arbitrary $x_{0}, u \in C$, we define an iterative algorithm by

$$
\left\{\begin{array}{l}
u_{n}=P_{C}\left(x_{n}-\lambda_{n} d_{n}\right), \\
x_{n+1}=\alpha_{n} u+\left(1-\alpha_{n}\right)\left(\left(1-b_{n}\right) u_{n}+b_{n} T u_{n}\right), \forall n \geq 0,
\end{array}\right.
$$

where $b_{n} \in(c, \mu] \subset(0,1)$ for some $c>0$ and $\mu<\min \{1,2 k\}$ for all $n \geq 0$, and $\left\{\alpha_{n}\right\} \subset(0, d] \subset$ $(0,1)$ such that $\sum_{n=0}^{\infty} \alpha_{n}=\infty$ and $\lim _{n \rightarrow \infty} \alpha_{n}=0$. Then, $\left\{x_{n}\right\}$ converges strongly to an element $x^{*}=P_{\Omega} u \in \Omega$, where $P_{\Omega}$ is the metric projection onto $\Omega$.

Proof. Using the fact that $P_{C}$ is nonexpansive and following the method in proof of Theorem 3.2 , we get the desired conclusion immediately.

Observe that every quasi-nonexpansive mapping is demicontractive. If, in Theorem $3.3, T$ is quasi-nonexpansive, then we have the following result.

Corollary 3.3. Let $C$ be a nonempty, closed and convex subset of a real Hilbert space H. Let $T: C \rightarrow C$ be quasi-nonexpansive mapping such that $I-T$ is demiclosed at zero. Assume that $\Omega:=\left\{x^{*} \in F(T): f\left(x^{*}\right)=0\right\} \neq \emptyset$. Let $\left\{x_{n}\right\}$ be a sequence defined by (3.21). Then, $\left\{x_{n}\right\}$ converges strongly to an element $x^{*}=P_{\Omega} u \in \Omega$.

If, in Theorem 3.2, the direction vector $d_{k}$ coincides with the gradient $\nabla f$, then we have the following result. 
Corollary 3.4. Let $E$ admit a weakly sequentially continuous duality mapping. Let $f: E \rightarrow \mathbb{R}$ be nonnegative differentiable convex function. Let $T: E \rightarrow E$ be a demicontractive mapping such that $I-T$ is demiclosed at zero. Assume that $\Omega:=\left\{x^{*} \in F(T): f\left(x^{*}\right)=0\right\} \neq \emptyset$. For arbitrary $x_{0}, u \in E$, define an iterative algorithm by

$$
\left\{\begin{array}{l}
u_{n}=x_{n}-\lambda_{n} J_{q}^{-1}\left(\nabla f\left(x_{n}\right)\right), \\
x_{n+1}=\alpha_{n} u+\left(1-\alpha_{n}\right)\left(\left(1-b_{n}\right) u_{n}+b_{n} T u_{n}\right), \forall n \geq 0,
\end{array}\right.
$$

where $b_{n} \in(c, \mu]$ for some $c>0$ and $\mu<\min \left\{1,\left\{\frac{q k}{c_{q}}\right\}^{\frac{1}{q-1}}\right\}$ for all $n \geq 0$, and $\left\{\alpha_{n}\right\} \subset(0, d] \subset$ $(0,1)$ such that $\sum_{n=0}^{\infty} \alpha_{n}=\infty, \lim _{n \rightarrow \infty} \alpha_{n}=0$,

$$
\lambda_{n}= \begin{cases}\frac{\rho_{n} f\left(x_{n}\right)}{\left\|\nabla f\left(x_{n}\right)\right\|^{p}}, & \nabla f\left(x_{n}\right) \neq 0 \\ 0, & \text { otherwise, }\end{cases}
$$

for $\inf _{\Gamma}\left[\rho_{n}\left(q-\rho_{n}\right)\right]>0$. Then, $\left\{x_{n}\right\}$ converges strongly to an element $x^{*}=P_{\Omega} u \in \Omega$.

If, in Theorem 3.2, we consider $E=H_{1} \times H_{2}$, where $H_{1}$ and $H_{2}$ are real Hilbert spaces, $T: E \rightarrow E$ given by $T(x, y)=\left(T_{1}(x), T_{2} y\right)$ is a $k$-strictly pseudocontractive mapping, and $f(x, y)$ : $E \rightarrow \mathbb{R}$ is a function defined by $f(x, y)=\frac{1}{2}|| A x-B y \|^{2}$, where $A: H_{1} \rightarrow H_{3}$ and $B: H_{2} \rightarrow H_{3}$ are bounded linear mappings, then we observe that $f$ is a convex and continuous function, and, for every $(x, y) \in H_{1} \times H_{2}$, we have $\nabla f(x, y)=\left(A^{*}(A x-B y),-B^{*}(A x-B y)\right)$. Moreover, letting $\left(x_{0}, y_{0}\right) \in H_{1} \times H_{2}, x_{n}=\left(z_{n}, y_{n}\right), u_{n}=\left(s_{n}, v_{n}\right)$, and $d_{n}=\nabla f\left(z_{n}, y_{n}\right)$ in (3.21), we obtain the following result.

Corollary 3.5. Let $H_{1}, H_{2}$ and $H_{3}$ be real Hilbert spaces. Let $T: H_{1} \rightarrow H_{1}$ and $S: H_{2} \rightarrow H_{2}$ be $k$-strictly pseudocontractive contractive mappings with constants $k_{1}$ and $k_{2}$, respectively. Let $A: H_{1} \rightarrow H_{3}$ and $B: H_{2} \rightarrow H_{3}$ be two bounded linear operators with their adjoint operators $A^{*}$ and $B^{*}$, respectively. Assume that $\Omega:=\{(z, y) \in F(T) \times F(S): A z=B y\} \neq \emptyset$. Let $s, z_{0} \in H_{1}$ and $v, y_{0} \in H_{2}$ be chosen arbitrarily, and let $\left\{\left(z_{n}, y_{n}\right)\right\}$ be a sequence defined by

$$
\left\{\begin{array}{l}
x_{0}, u \in H_{1}, y_{0}, v \in H_{2} \text { chosen arbitrarily, } \\
s_{n}=z_{n}-\lambda_{n} A^{*}\left(A z_{n}-B y_{n}\right) \\
z_{n+1}=\alpha_{n} u+\left(1-\alpha_{n}\right)\left(\left(1-b_{n}\right) s_{n}+b_{n} T_{1} s_{n}\right) \\
v_{n}=y_{n}-\lambda_{n} B^{*}\left(B y_{n}-A z_{n}\right), \\
y_{n+1}=\alpha_{n} v+\left(1-\alpha_{n}\right)\left(\left(1-b_{n}\right) v_{n}+b_{n} T_{1} v_{n}\right), \forall n \geq 0
\end{array}\right.
$$

where $b_{n} \in(c, \mu]$ for $\mu=\min \{1,2 k\}$ for all $n \geq 0$, and $\left\{\alpha_{n}\right\} \subset(0, d] \subset(0,1)$ such that $\sum_{n=0}^{\infty} \alpha_{n}=$ $\infty$ and $\lim _{n \rightarrow \infty} \alpha_{n}=0$. Then $\left\{x_{n}\right\}=\left\{\left(z_{n}, y_{n}\right)\right\}$ converges strongly to an element $\left(z^{*}, y^{*}\right) \in \Omega$.

Remark 3.1. Our main results provide an affirmative answer to Question 1.1. Theorems 3.2 extends the results of Zhao $[18,19]$ in the sense that our result provides strong convergence for the class of demicontractive mappings, which is more general than quasi-nonexpansive mappings. In addition, Theorem 3.2 extends the results of Zhao and Zhang [20] and Giang et al. [10] in the sense that our strong convergence result is for the general split fixed point problem governed by demicontractive mappings in Banach spaces instead of Hilbert spaces.

\section{REFERENCES}

[1] Ya. Alber, A. Iusem, M. Solodov, Minimization of nonsmooth convex functionals in Banach spaces, J. Convex Anal. 4 (1997), 235-254. 
[2] C. Byrne, A. Moudafi, Extensions of the CQ algorithms for the split feasibility and split equality problems, J. Nonlinear Convex Anal. 18 (2017), 1485-1496.

[3] Y. Censor, A. Segal, The split common fixed point problem for directed operators, J. Convex Anal. 16 (2009), 587-600.

[4] S.S. Chang, L. Wang, Y. Zhao, On a class of split equality fixed point problems in Hilbert spaces, J. Nonlinear Var. Anal. 1 (2017), 201-212.

[5] A. Gibali, N.H. Ha, N.T. Thuong, T.H. Trang, N.T. Vinh, Polyak's gradient method for solving the split convex feasibility problem and its applications, J. Appl. Numer. Optim. 1 (2019), 145-156.

[6] S.S Chang, J. C. Yao, J.J. Kim, L. Yang, Iterative approximation to convex feasibility problems in Banach spaces, Fixed Point Theory Appl. 2007 (2007), 046797.

[7] R. Chen, J. Wang, H. Zhang; General split equality problems in Hilbert spaces, Fixed Point Theory Appl. 2014 (2014), 35.

[8] C.E. Chidume, P. Ndambomve, A.U. Bello, M.E. Okpala, The multiple-sets split equality fixed point problem for countable families of multi-valued demi-contractive mappings, Int. J. Math. Anal. 9 2015, 453-469.

[9] M. Eslamian, General algorithms for split common fixed point problem of demicontractive mappings, Optimization, 65 (2016), 443-465.

[10] D.M. Giang, J.J. Strodiot, V.H. Nguyen, Strong convergence of an iterative method for solving the multipleset split equality fixed point problem in a real Hilbert space, Rev. R. Acad. Cienc. Exactas Fis. Nat. Ser. A Math. RACSAM 111 (2017), 983-998.

[11] A.R. Khan, M. Abbas, Y. Shehu, Q.H. Ansari, A general convergence theorem for multiple-set split feasibility problem in Hilbert spaces, Carpathian J. Math. 31 (2015), 349-357.

[12] G. Lopez, V. Martin-Marquez, F. Wang, H.K. Xu, Solving the split feasibility problem without prior knowledge of matrix norms, Inverse Probl. 28 (2012), 085004.

[13] W. Takahashi, Nonlinear Functional Analysis, Kindikagaku, Tokyo, 1988.

[14] P.E. Mainge, Strong convergence of projected subgradient methods for nonsmooth and non- strictly convex minimization, Set-Valued Anal. 16 (2008), 899-912.

[15] H.K. Xu, Inequalities in Banach spaces with applications, Nonlinear Anal. 16 (1991), 1127-1138.

[16] H.K. Xu, Another control condition in an iterative method for nonexpansive mappings, Bull. Austral. Math. Soc. 65 (2002), 109-113.

[17] H. Zhang, Y. Su, Convergence theorems for strict pseudo-contractions in q-uniformly smooth Banach spaces, Nonlinear Anal. 71 (2009), 4572-4580.

[18] J. Zhao, Solving split equality fixed-point problem of quasi-nonexpansive mappings without prior knowledge of operator norms, Optimization, 64 (2015), 2619-2630.

[19] J. Zhao, S. Wang, Mixed iterative algorithms for the multiple-set split equality common fixed-point problems without prior knowledge of operator norms, Optimization, 65 (2016), 1069-1083.

[20] J. Zhao, H. Zhang, Solving split common fixed-point problem of firmly quasi-nonexpansive mappings without prior knowledge of operator norms, Abstr. Appl. Anal. 2014 (2014), Article ID 389689.

[21] H. Zhou, Convergence theorems for $k$-strict pseudo-contractions in 2-uniformly smooth Banach spaces, Nonlinear Anal. 69 (2008), 3160-3173. 